\title{
Effects of Soil Compaction in the Fight against Unpaved Roads Degradation Due to Erosion Caused by Heavy Rain: Proposition of a Specific CBR Evaluation Model
}

\author{
Timothée Thierry Odi Enyegue1, Eric Flavien Mbiakouo-Djomo², Hugues Tsanga1, \\ Fabien Kenmogne ${ }^{3}$, Blaise Ngwem Bayiha ${ }^{3}$, Gilbert Tchemou ${ }^{3}$, Ebenezer Njeugna ${ }^{4}$, \\ Didier Fokwa ${ }^{3}$
}

\begin{abstract}
${ }^{1}$ Laboratory of Mechanics, Doctorate Unit of Engineering Sciences, Doctorate School of Fundamental and Applied Sciences, University of Douala, Douala, Cameroon

${ }^{2}$ Department of Rural Engeineering, FASA, University of Dschang, Dschang, Cameroon

${ }^{3}$ Civil Engineering Department, Higher Technical Teacher's Training College, University oh Douala, Douala, Cameroon

${ }^{4}$ Mechanics Engineering Department, Higher Technical Teacher's Training College, University oh Douala, Douala, Cameroon

Email: oditimothee@yahoo.fr
\end{abstract}

How to cite this paper: Enyegue, T.T.O., Mbiakouo-Djomo, E.F., Tsanga, H., Kenmogne, F., Bayiha, B.N., Tchemou, G., Njeugna, E. and Fokwa, D. (2021) Effects of Soil Compaction in the Fight against Unpaved Roads Degradation Due to Erosion Caused by Heavy Rain: Proposition of a Specific CBR Evaluation Model. Engineering, 13, 95-104.

https://doi.org/10.4236/eng.2021.133008

Received: August 17, 2020

Accepted: February 26, 2021

Published: March 2, 2021

Copyright $\odot 2021$ by author(s) and Scientific Research Publishing Inc. This work is licensed under the Creative Commons Attribution International License (CC BY 4.0).

http://creativecommons.org/licenses/by/4.0/ (c) (i) Open Access

\begin{abstract}
Unpailt roads are generally subject to erosion, when they need to be bitumen, civil engineers need to know the geotechnical capabilities of the soil layers to be used as support, among these capabilities, for example, soil characteristics to withstand erosion. CBR has often been used to classify these soils according to their compaction. In this article, we propose a correlation between CBR and eroded soil mass through a simulator. Indeed, in this article we show that using a simulator, soils can be classified according to their ability to withstand water erosion, whether internal or external. Indeed it is shown that the mass of eroded soil is related to the compaction capacity of the soil just as the CBR also has. We study the effects and influence of soil compaction on the ability of an unpaved road to resist erosion caused by falling raindrops. To do this, lateritic soil is submitted to different compaction pressures. The compacted soil is then submitted to CBR test and rain fall through a mini rain simulator. Correlations between eroded soil masse and compaction pressure as well as CBR are derived. The study shows that the compaction reduces the erodibility and increases the bearing capacity of soil. The formula obtained is significant because we have a new way of evaluating soils in the laboratory.
\end{abstract}




\section{Keywords}

Compaction, Erosion, Lateritic Soil, Rain Drop, Unpaved Roads

\section{Introduction}

In African rural areas, in the forests and in some villages, non-bitumen roads are numerous and are exposed to erosion due to the rainfall of the regions, which causes a real problem when it is necessary to level regularly. A better solution would be to properly fill these roads by using proper soil layers during construction. With this in mind, rain simulation methods are highly suitable for factor study trials, such as Jordan and Martinez studies, on surface runoff and sediment production on unpaved forest roads in the Los Alcornocales Nature Park (southern Spain) using a simple portable rain simulator at an intensity of $72 \mathrm{~mm} \cdot \mathrm{h}^{-1}$ and show the importance of vegetation cover, they advocate reducing the angle of the bank by about $40 \%$ and increasing the vegetation cover to $35 \%$ $40 \%$ to keep erosion below $18 \mathrm{~g} \cdot \mathrm{m}^{-2}$ [1]. Another study showed that soil texture and the presence of rock fragments can reduce erosion and that shorelines can be considered the main source of sediment on sites, but the function of unpaved forest roads as source points for runoff production is more important [2]. For the problem posed by these researchers that is: it is not practical on all dirt roads but we prefer as solution the control of first-hand treatment, for the protection of properties and humans. Erosion of Cohesive Soils deposes depend on the nature of clay [3]. Other studies have shown that the geotechnical quality of a soil can be improved by giving it good mechanical properties for road construction purposes [4]. Particularly in Cameroon country, and more precisely in some towns like Afan-Egon, in the South region of the country, or in Mindourou in the East region, where roads are not yet paved, laterite soil is sometimes used as the upper layer of the road surface. More recently, Odi Enyegue and coworkers [5], explored parameters that affect the dynamics of water erosion, via a device built, nowadays, the road is everywhere the main way of internal transport and trade in each city, or country. To build a road, engineers use several techniques, including leveling by scraping, or leveling by adding new layers of soil. It sometimes happens in certain places that this layer is washed away during the rain, despite the ingenious techniques applied, that is the well-known erosion phenomenon [4]. This is probably the reason why many researchers have put emphases on analytical and experimental studies of erosions dynamics, in order to predict or avoid them.

Having the ability to vary the soil slope, as well as the rainfall intensity, they found that the device is a good tool to simulate the behavior of all types of soil under the action of rain. In present study, we reconsider the device built in previous works of Odi Enyegue et al., where we study the effects of some important parameters, namely the influence of compaction on soil losses as well as 
its bearing capacity. This simulator will then allow us to find a correlation between the weights of eroded soil and the CBR (California Bearing Report) which is a parameter of classification of soils of good geotechnical characteristics.

\section{Materials and Method}

\subsection{Materials}

To carry out this study, we used as materials: molds in the shape of a parallelepiped, made of solid wood with metal at each angle, in order to resist transverse pressure; a laboratory controlled press; 80 microns and $2 \mathrm{~mm}$ sieves; and the OEF (Odi Enyegue Fokwa) rain simulator improved by adding a contour of plexig as $0.5 \mathrm{~m}$ high, to reduce soil losses due to splash effects, and also, improve the irrigation system; now made up of 6 watering cans and 03 branches. Figure 1 shows the diagram of the improved OEF simulator.

The stuff used is a lateritic soil made up of $80 \%$ fine particles. Figure 2 shows

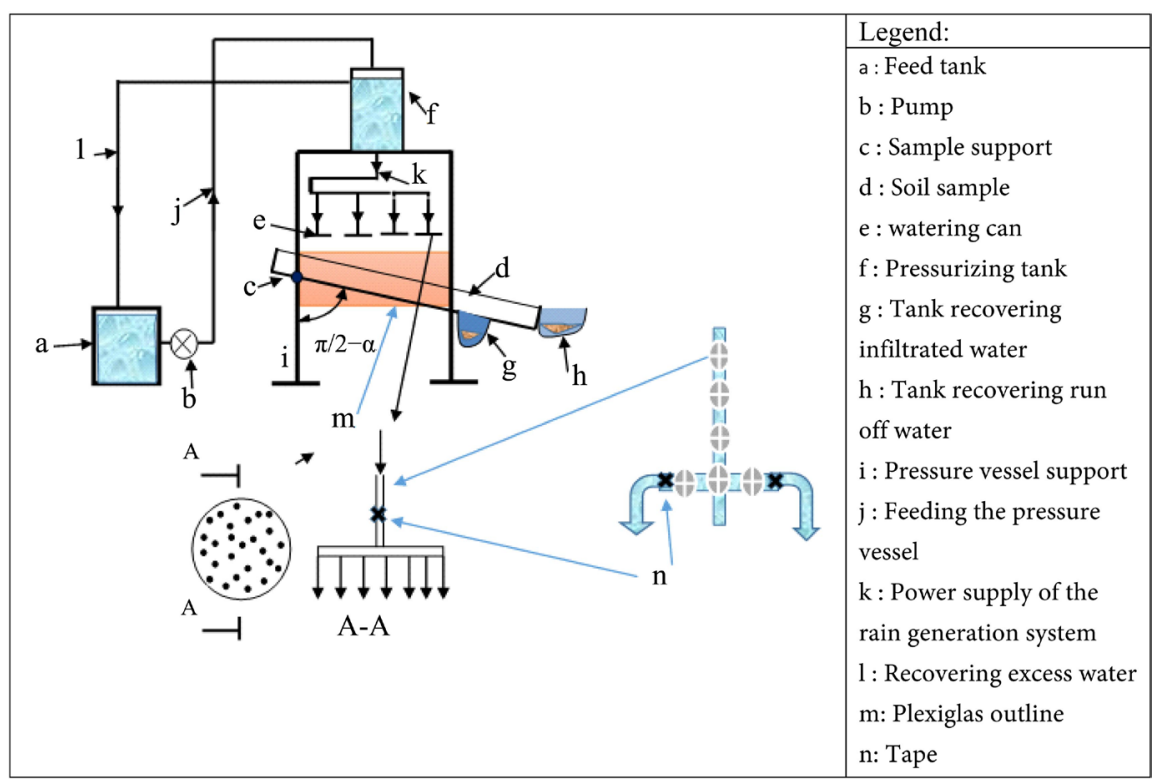

Figure 1. The mini rain simulator, produced by [5] and improved by a revision of the sprinkler system and addition of an outlined Plexiglas.

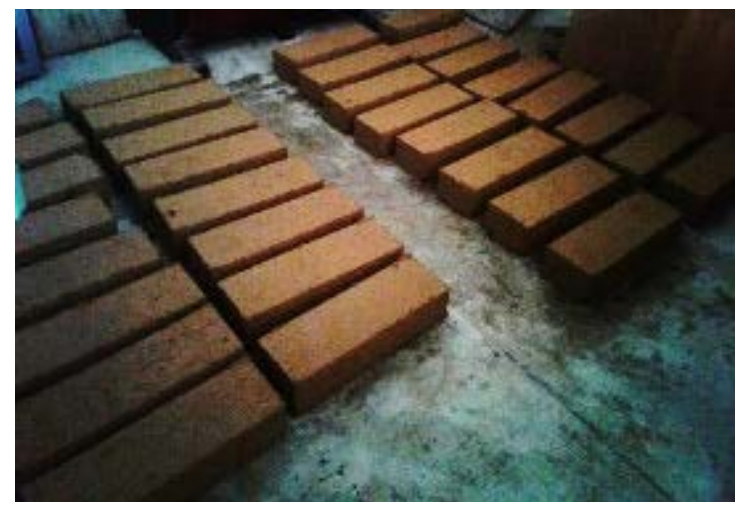

Figure 2. Image of the lateral earth blocks, used as a sample. 
the photograph of the compacted soil samples in the molds adapted to the tank of the experimental device. The samples consist of soil blocks of dimension $0.2 \times$ $0.4 \times 0.15\left(\mathrm{~m}^{3}\right)$.

The ensenble of the material used complies with isO TS 19392-1 requirements that rain erosion can be simulated by a constant pressure stream of rainwater on a soil sample.

\subsection{Method}

The method used to study the influence of compaction in the fight against the erosion of unpaved roads is as follows: A sample of lateritic soil is collected, then dried, and separated into the fine particles (smaller diameter or equal to 2 $\mathrm{mm}$ ) and coarse particles, to assess the texture. We next proceed to the composition of sample in the desired proportions, by mixing a proportion of fine particles with a proportion of coarse particles. Next, a volume of water is gradually added throughout the process until obtaining a homogeneous soil. In order to study the effects of compaction on road erosion, these samples can be subjected to compression stresses, thanks to a press adapted to the circumstance. According to the surveys, [6] [7] [8] [9] have shown that compression of soil can improve its shear strength as well as its CBR From laboratory tests, one can check this by comparing the soils weights detached from blocks, and finding a correlation between these weights and their CBR.

The compacted soil is then put in the sample tank (d) of the rain simulation device. The soil slope is kept constant for all the tests, and the watering system is adjusted so as to maintain constant rain intensity for the duration of each test. This is possible when the water outlet pressure is kept constant, and this in order to satisfy the following equation [5]:

$$
P_{s}=\rho_{e} \cdot g \cdot H+P_{a t m},
$$

where $P_{s}$ is the rainwater outlet pressure $(\mathrm{Pa}), \rho_{e}$ the water density, whose value is $\left(1000 \mathrm{~kg} \cdot \mathrm{m}^{-3}\right), g$ is the gravity intensity $\left(g=9.8 \mathrm{~m} \cdot \mathrm{s}^{-2}\right), P_{a t m}$ is the atmospheric pressure $\left(P_{a t m}=1.01325 \times 10^{5} \mathrm{~Pa}\right)$, while $H$ is the water height $(\mathrm{m})$, denoting the distance between the water level from the tank, and the outlet level of water. The water height is kept constant thanks to the discharge pump (b), which supplies the tank, and also thanks to the excess water transfer pipe, the set regularly checking the principle of the following dynamics [5]:

$$
Q_{p}=Q_{a}+Q_{r},
$$

in which $Q_{p}$ is the flow of water pumped back by the pump (L/s), $Q_{a}$ the flow of sprinkled water and $Q_{r}$ the flow of water returned to the tank (a).

At the beginning the flow of the sprayed water is first evaluated, corresponding to the volume of water collected at the end of each test. For this, we carefully choose the durations of each test at the valve openings. Then for each fixed time interval, the pump is activated and each volume of water is collected in different 
containers. This technique draws up the table of watering rates corresponding to each duration of the test. From each flow, the intensity of rain (I) simulated is given by the following formula:

$$
I=\frac{V}{S \cdot t},
$$

In which $V$ is the volume (expressed in L), $S$ is the area of the watered surface $\left(\mathrm{m}^{2}\right)$ and $t$ the watering time. $I$ can also be given as a function of the watering rate as follows:

$$
I=\frac{Q_{a}}{S} .
$$

After having drawn up the table containing the values of intensities, we then proceed to make different tests, by submitting the samples to different intensities of simulated rain. The eroded soil particles are collected in the container provided for this purpose. Each test is repeated successively four times, while the eroded soil particles collected are weighed, as well as the waters collected. The weight recorded is the average value of all weights, which can be given by the following formulas (5), used in our previous work [5]:

$$
m_{i}=m_{m e l(i)}-\rho_{e} V_{i} g
$$

and

$$
m=\frac{1}{4} \sum_{i=1}^{4} m_{i}
$$

\section{Data for Experiments}

In order to make our experiments, we have drawn up the following data as shown in Table 1.

The procedure consists of fixing the value of the rain intensity to the simulator and gradually varying different soil samples. The zero-bar compaction sample corresponds to the uncompressed soil, that is a soil introduced into the mold, then saturated with water, which is then left to dry for a week. From this

\begin{tabular}{|c|c|c|c|c|c|c|c|c|c|c|c|c|}
\hline \multicolumn{13}{|c|}{ The slope of the soil chosen for experiments is $8.75 \%$ and the watered surface of the block is $0.32 \mathrm{~m}^{2}$} \\
\hline \multicolumn{13}{|c|}{ Rain simulator data } \\
\hline Time (s) & \multicolumn{4}{|c|}{60} & \multicolumn{4}{|c|}{90} & \multicolumn{4}{|c|}{120} \\
\hline Volume of water (L) & 7.5 & 15 & 22.5 & 34.5 & 11.25 & 22.5 & 33.75 & 51.75 & 15 & 30 & 45 & 69 \\
\hline Volume of water flow L/S & 0.125 & 0.25 & 0.375 & 0.575 & 0.125 & 0.25 & 0.375 & 0.575 & 0.125 & 0.25 & 0.375 & 0.575 \\
\hline Intensity of simulated rain (mm) & 0.391 & 0.781 & 1.172 & 1.8 & 0.391 & 0.781 & 1.172 & 1.8 & 0.391 & 0.781 & 1.172 & 1.8 \\
\hline
\end{tabular}
procedure one gets a non-compacted block but therefore the cohesion of the particles is non-zero.

Table 1. Summary of experimental data. 


\section{Results and Discussions}

The results of measurements are shown in the figures below. The curves in Figures 3-5 show the effects of compaction on soil losses, when these different blocks are subjected to simulated rain beats over a period of $120 \mathrm{~s}$. It can be noted in these Figures that for the same intensities of rain, the curve that corresponds to a natural soil, not compacted is above all curves and differs from the other curves by a large loss of soil: A non-compacted area of $0.32 \mathrm{~m}^{2}$, would lose about 250 to $400 \mathrm{~g}$ of lateritic soil, for a rainfall time of $120 \mathrm{~s}$. It can also be noted that, the evolutionary curve of non-compacted soil loss has an exponentially increasing trend depending on the intensity of the rain. But by observing the trend

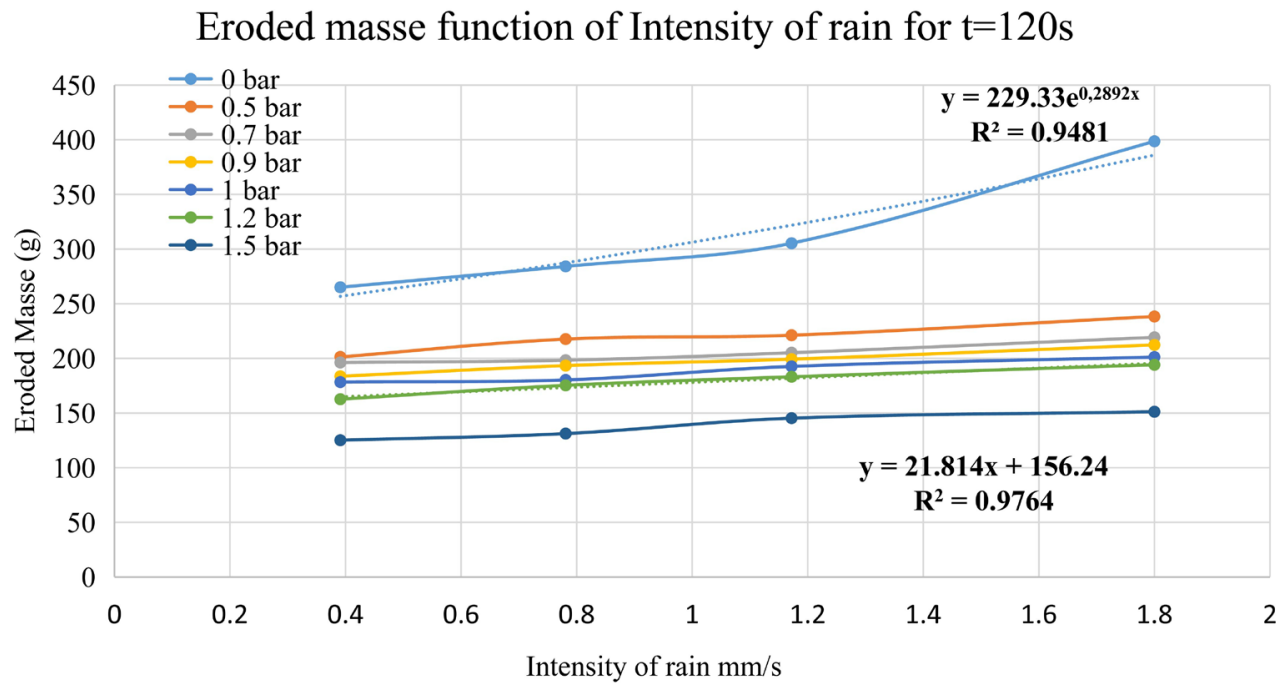

Figure 3. Visualization curves of the behaviour of blocks compacted at different pressures and subjected to the same rainfall intensities, for $120 \mathrm{~s}$.

Eroded masse of soil function to rain intensity for $\mathrm{t}=90 \mathrm{~s}$

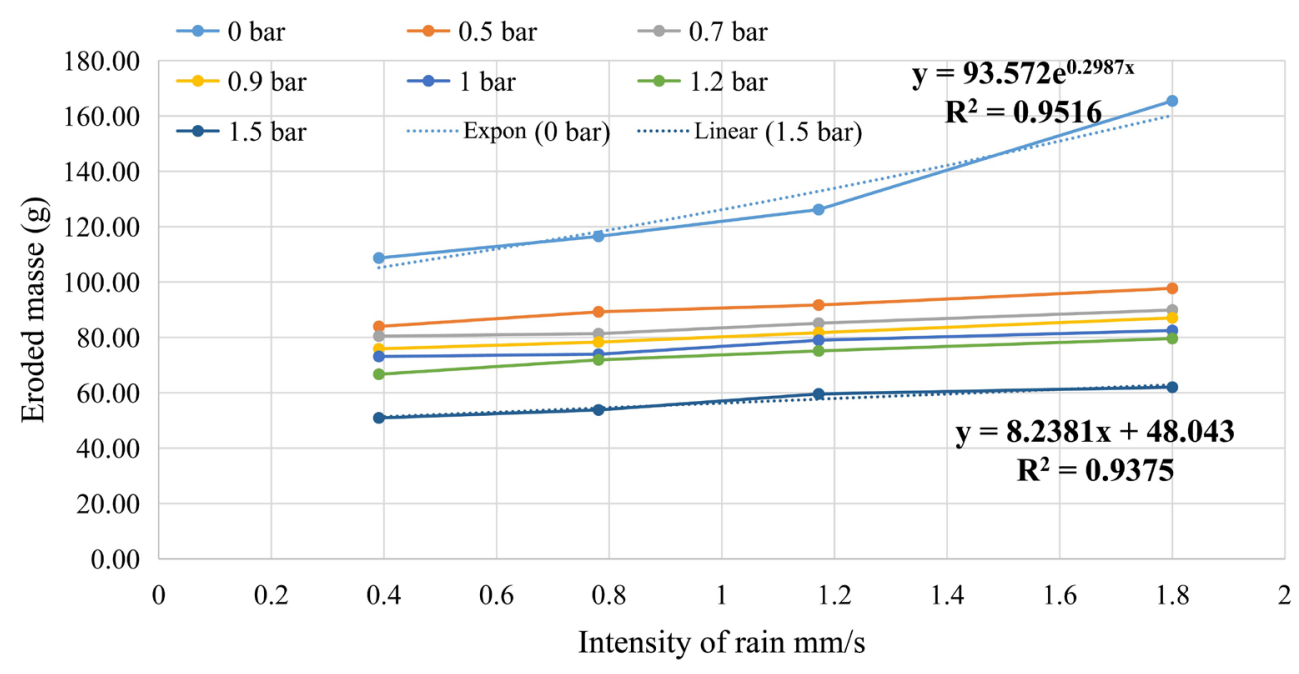


Figure 4. Visualization curves of the behaviour of blocks compacted at different pressures and subjected to the same rainfall intensities, for $90 \mathrm{~s}$.

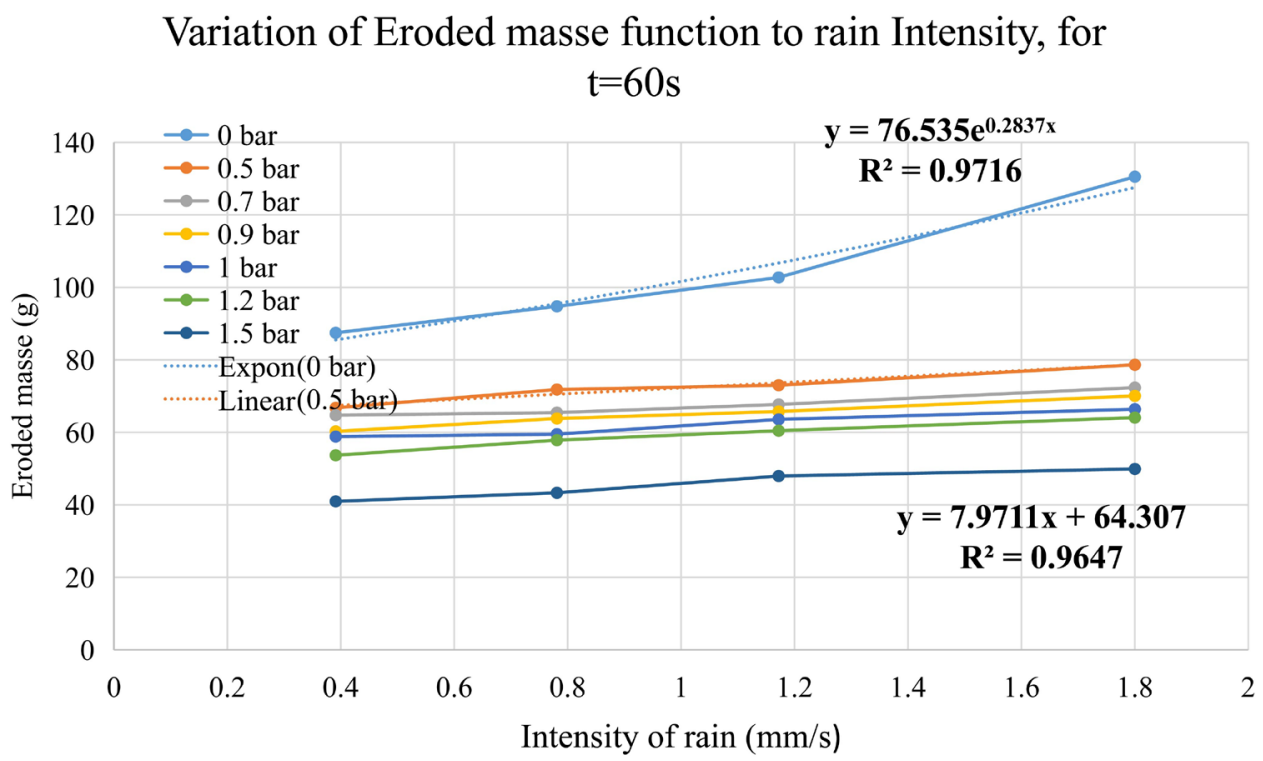

Figure 5. Visualization curves of the behaviour of blocks compacted at different pressures and subjected to the same rainfall intensities, for $60 \mathrm{~s}$.

of other curves, we observe a linear growth with the increasing in the rainfall intensity. Another observation can be made through these different curves: The curves representing each degree of compaction are superimposed on top of each other, so that the lowest curves are those with the largest compaction. It can then be said that compaction reduces soil losses thus, one can better understand why the CBR test, whose standard defines bears the reference NF P 94-078, allows the mechanical characterization of natural soils and compacted soils in embankments. The studies of Gullu and Fedakar [10] confirm this observation.

It is obvious from Figures 3-5 that, the lost soil weight also increases with the increasing of the rain duration.

In Figures 6-8, we can clearly see that soil compaction reduces soil loss, and therefore it is important in the construction of road, to improve the foundation layer and under foundation by carefully selecting its type of soil from below and making sure that it is well compacted. This can better prevent the risks of degradation due to internal or external erosion. The yellow curve above the other curves is the evolution curve of soil loss for the largest rainfall intensity we have stimulated. This curve follows an exponential decrease as the compacting pressure increases.

According to the above analysis of different erosion evolution curves, the increasing in soil compaction improves its capacity to resist the detachment of its particles. The CBR is a parameter used to characterize the degree of compaction, but also the nature of soil. According to a survey (Fasanmade, Adeyemi, and Eze 2015) found that the geotechnical characteristics of a soil could be improved, poor lateritic soil from another soil of good characteristics. Their studies have shown that 
the Californian lift ratio (CBR) used to determine the resistance of lateritic sub-grade and sub-base materials is a very good geotechnical parameter, and the Variation of eroded masse function to compaction pressure

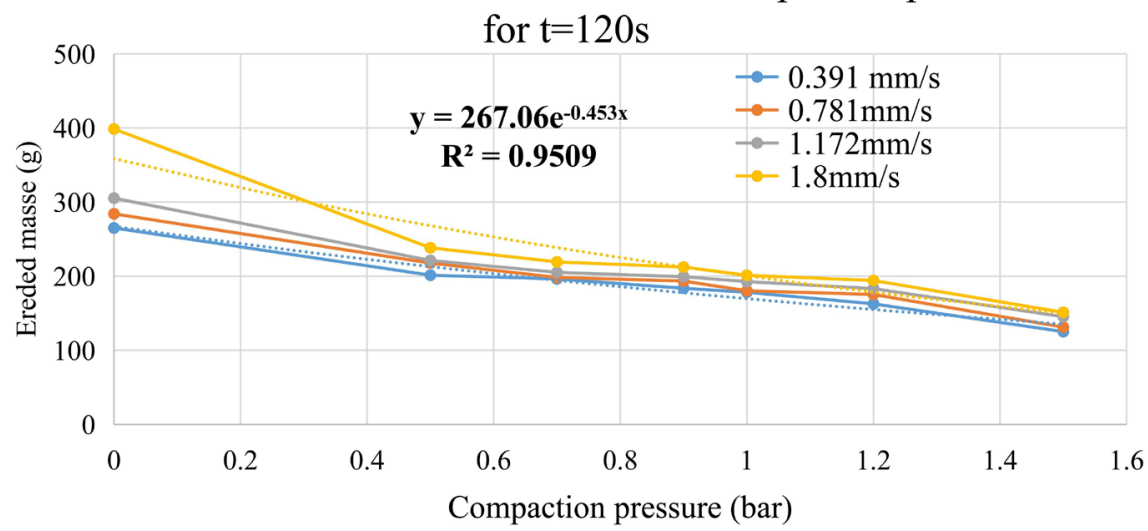

Figure 6. Evolution of soil loss with compaction for different values of the intensity of the beating of the rains for $\mathrm{t}-120 \mathrm{~s}$.

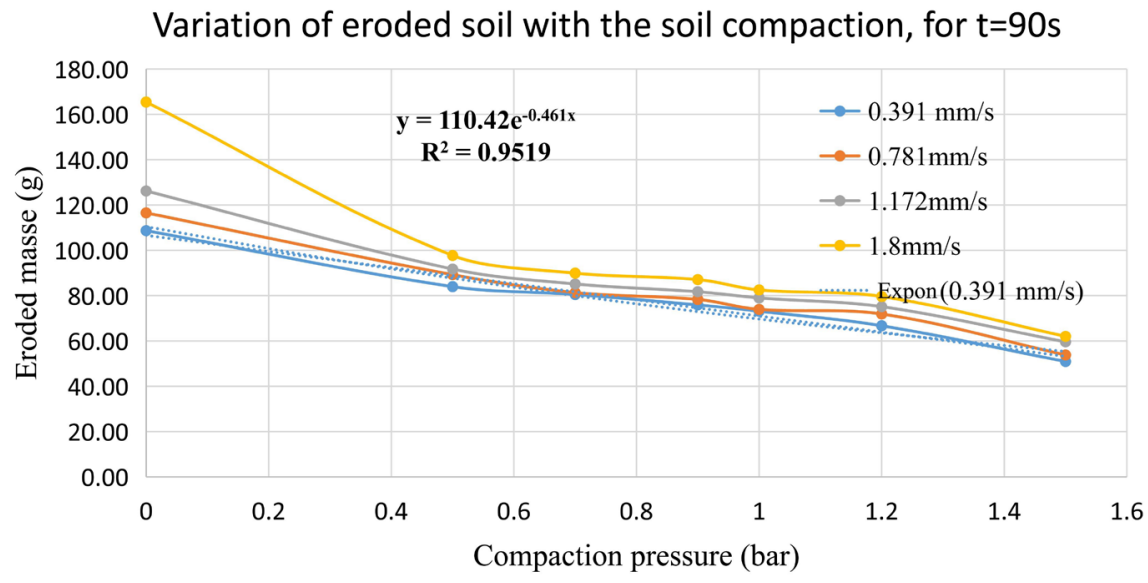

Figure 7. Evolution of soil loss with compaction for different values of the intensity of the beating of the rains for $\mathrm{t}-90 \mathrm{~s}$.

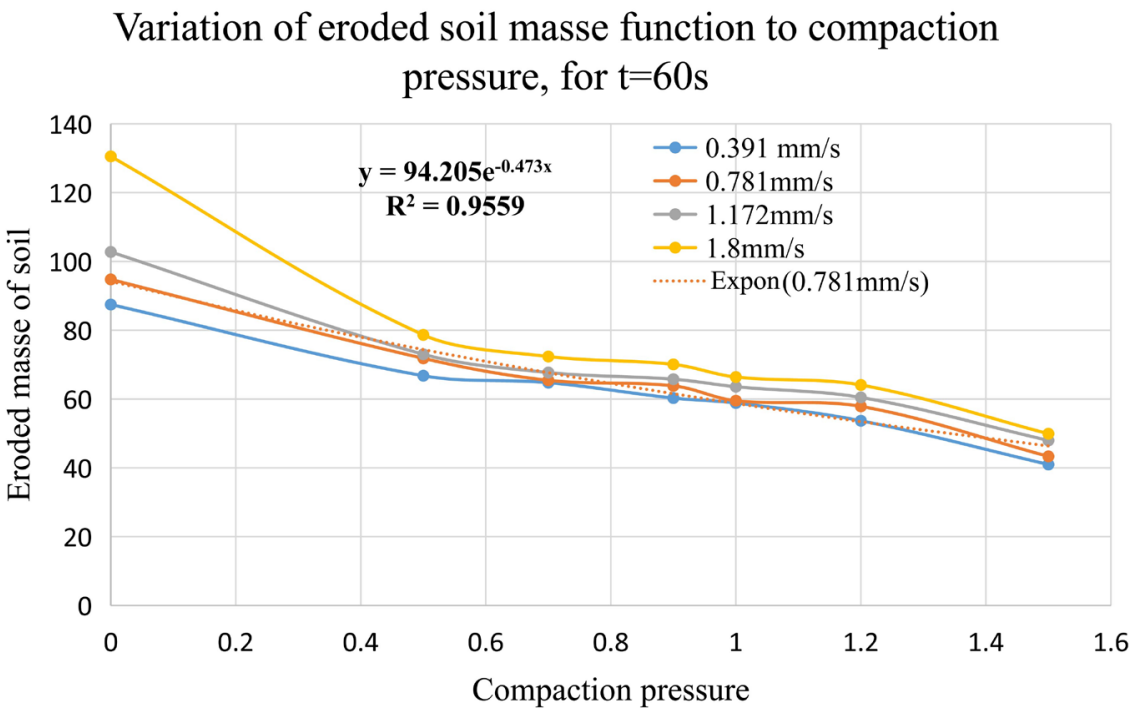


Figure 8. Evolution of soil loss with compaction for different values of the intensity of the beating and rains for $\mathrm{t}-60 \mathrm{~s}$.

mechanical stabilization of soil mixtures can be made by lateritic soil with good geotechnical characteristics.

There is also a correlation between eroded soil weight $(m)$ and compaction pressure $(p)$. The evolution of these curves reveals a decrease in the weight loss, that can be modeled by a function of the form:

$$
m=A \mathrm{e}^{-a p} .
$$

where $A$ (expressed in $\mathrm{g}$ ) and $\mathrm{a}$ (in $\mathrm{Pa}^{-1}$ ) are positive and empirical constants, which can be determined experimentally taking into account the texture, composition and water content of the soil and $p$ is the compaction pressure. The parameter $A$ is necessarily proportional to the weight of soil lost when it is in its natural non-compacted state. Since $P$ is proportional to the CBR, one can then obtain from the Equation (6), a function of the form:

$$
m=m_{0} \mathrm{e}^{-\lambda \cdot \mathrm{CBR}}
$$

with $m_{0}$ the weight of soil lost, when it is subjected to the effect of rain in its natural state. From the above Equation (6), one can deduce the following expression of CBR specific to compaction:

$$
\mathrm{CBR}=-\frac{1}{\lambda} \log \left(\frac{m}{m_{0}}\right)
$$

\section{Conclusion}

The purpose of the present work was the study of the influence of compaction in the fight against erosion of unpaved roads. For this, we took a sample of lateritic soil, which are collected and compacted in order to measure, according to the compaction rate, losses of soil eroded by simulated rains of known intensity. As a result, it appears that compaction reduces the risk of soil loss by water erosion, justifying then the use of CBR as a geotechnical parameter in the case of road construction engineering, for the classification of soils, determining the CBR requires state-of-the-art equipment, which is not always within the reach of all researchers. The technic outlined here can therefore be used in the laboratory to classify the composite materials likely to be used in foundations or under foundation of roads. Our future research is focused on the classification of soils as mentioned above.

\section{Conflicts of Interest}

The authors declare no conflicts of interest regarding the publication of this paper.

\section{References}

[1] Jordan, L. and Martínez-Zavala, A.J. (2008) Soil Loss and Runoff Rates on Unpaved Forest Roads in Southern Spain after Simulated Rainfall. Forest Ecology and Man- 
agement, 255, 913-919. https://doi.org/10.1016/j.foreco.2007.10.002

[2] Jordán-López, A., Martínez-Zavala, L. and et Bellinfante, N. (2009) Impact of Different Parts of Unpaved Forest Roads on Runoff and Sediment Yield in a Mediterranean Area. Science of The Total Environment, 407, 937-944. https://doi.org/10.1016/j.scitotenv.2008.09.047

[3] Raudkm, A.J. and Tan, S.K. (1984) Erosion of Cohesive Soils. Journal of Hydraulic Research, 22, 217-233. https://doi.org/10.1080/00221688409499380

[4] Fasanmade, P.A., Adeyemi, G.O. and Eze, E.O. (2015) The California Bearing Ratio (CBR) of Some Mechanically Stabilised Laterite Sub-Base Soils along the Ibadan-Oyo Road, Southwestern Nigeria. African Journal of Science, Technology, Innovation and Development, 7, 122-125. https://doi.org/10.1080/20421338.2015.1023638

[5] Enyegue, T.T.O., Fokwa, D., Mbiakouo-Djomo, E.F. and Njeugna, E. (2019) A Simple Device to Evaluate the Influence Parameters of the Water Erosion of Bare Sandy-Clay Soils of the City of Douala. Engineering, 11, 819-827. https://doi.org/10.4236/eng.2019.1112056

[6] Cui, Y.-J. (1993) Etude du comportement d'un limon compacté non saturé et de sa modélisation dans un cadre élasto-plastique. PhD Thesis, Mécanique des matériaux [physics.class-ph]. Ecole Nationale des Ponts et Chaussées.

[7] Delage, P. and Fry, J.-J. (2000) Comportement des sols compactés: Apports de la mécanique des sols non saturés. Revue Française de Géotechnique, N²92, 17-29. https://doi.org/10.1051/geotech/2000092017

[8] Alonso, E. (2005) Compactage et comportement de sols fins humides. Revue Française de Géotechnique, $\mathrm{N}^{\circ}$ 111, 33-43. https://doi.org/10.1051/geotech/2005111033

[9] Bouklikha, R. and Mechernene, M. (2016) L'effet du compactage sur les caracteristiques de permeabilite et de resistance d'un sol fin. Universite Abou Bekr Belkaid Tlemcen UABT, Département de Génie Civil.

[10] Güllü, H. and Fedakar, H.İ. (2018) Use of Factorial Experimental Approach and Effect Size on the CBR Testing Results for the Usable Dosages of Wastewater Sludge Ash with Coarse-Grained Material. European Journal of Environmental and Civil Engineering, 22, 42-63. https://doi.org/10.1080/19648189.2016.1179678 